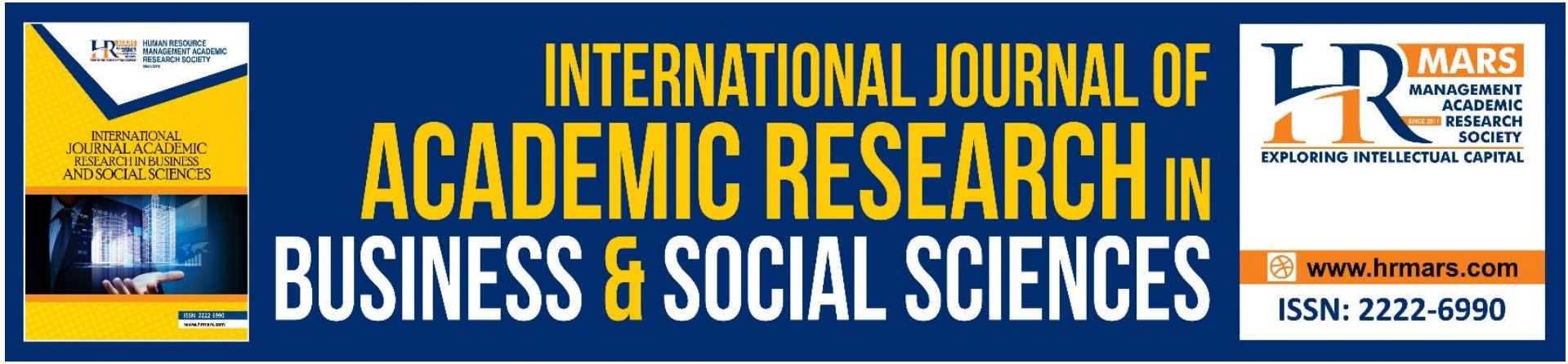

\title{
Incorporating Online Manga and Manhwa to Entice Cognitive Reading and Writing Strategies: A Conceptual Paper
}

\section{Natasha Binti Zuhaimi, Amalia Qistina Castenada Abdullah}

To Link this Article: http://dx.doi.org/10.6007/IJARBSS/v11-i7/10433

DOI:10.6007/IJARBSS/v11-i7/10433

Received: 04 May 2021, Revised: 10 June 2021, Accepted: 27 June 2021

Published Online: 07 July 2021

In-Text Citation: (Zuhaimi \& Abdullah, 2021)

To Cite this Article: Zuhaimi, N. B., \& Abdullah, A. Q. C. (2021). Incorporating Online Manga and Manhwa to Entice Cognitive Reading and Writing Strategies: A Conceptual Paper. International Journal of Academic Research in Business and Social Sciences, 11(7), 169-182.

Copyright: (c) 2021 The Author(s)

Published by Human Resource Management Academic Research Society (www.hrmars.com) This article is published under the Creative Commons Attribution (CC BY 4.0) license. Anyone may reproduce, distribute, translate and create derivative works of this article (for both commercial and non-commercial purposes), subject to full attribution to the original publication and authors. The full terms of this license may be seen at: http://creativecommons.org/licences/by/4.0/legalcode

Vol. 11, No. 7, 2021, Pg. 169 - 182

Full Terms \& Conditions of access and use can be found at http://hrmars.com/index.php/pages/detail/publication-ethics 


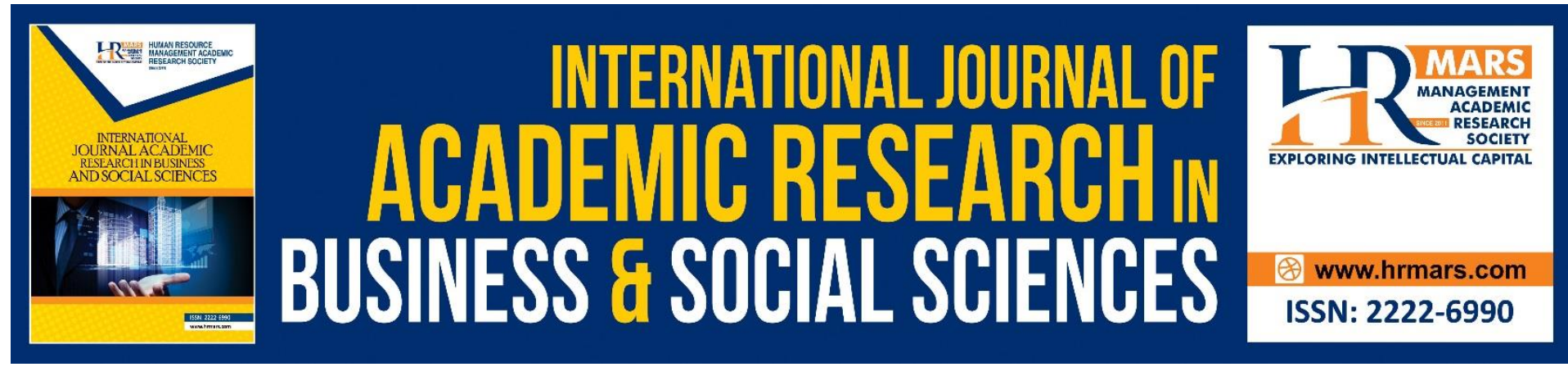

\title{
Incorporating Online Manga and Manhwa to Entice Cognitive Reading and Writing Strategies: A Conceptual Paper
}

Natasha Binti Zuhaimi ${ }^{1}$, Amalia Qistina Castenada Abdullah²

${ }^{1}$ Master Student, University Putra Malaysia, Serdang Selangor, Malaysia, ${ }^{2}$ Senior Lecturer

(PhD), University Teknologi MARA, Kampus Kuala Pilah, Negeri Sembilan, Malaysia

Email: natashazhm@gmail.com, amali608@uitm.edu.my

\begin{abstract}
This study aims to examine the strategy of incorporating Online Manga and Manhwa to entice cognitive reading and writing strategies. To become good readers and writers, students need to be immersed with the story. Exposure to literacy is not solely by reading physical books. The existence of technology has broadened the horizon of reading materials to be more striking to readers with various genres through the internet realm. In recent years, online Manga and Manhwa have garnered an innumerable number of readers internationally in promoting their culture and entertainment as the primary source of attraction. Multimodality and Dual-coding theory have been used interchangeably to incorporate Online Manga and Manhwa in the field of language and literacy. The multi-modals in Manga and Manhwa have crafted a path for learners to be creative, imaginative, and critical thinkers. With the emergence of Multimodality and Dual-coding theory, the author discussed the potentials and problems of incorporating online Manga and Manhwa in language and literacy. As an innovation to entice students' reading and writing strategies, the author has adopted a strategy from past research to be incorporated to implement the technique of using Online Manga and Manhwa.
\end{abstract}

Keywords: Manga, Manhwa, Reading, ESL, Multimodality

\section{Introduction}

The integration of technology has opened many sites offering a range of reading materials. One popular online reading is Manga and Manhwa (Yamada et al., 2004; Kultura, 2017). Manga has garnered tremendous popularity internationally because of its unique ability to grow with their followers, henceforth has led an increased interest towards its counterpart by the name of Manhwa (Kultura, 2017). Generally, Manga is originated from Japan, whereas Manhwa is from Korea. The name Manga and Manhwa are cognates of the Chinese word Manhua which means "impromptu sketches." Manhwa grew out of Japanese influences during Korea's occupation from 1910 to 1945, thereby causing the fluctuation of cartoons and comic books (Kultura, 2017). Due to their intense fame worldwide, Manga and Manhwa have 
been translated into several languages and often in the English language to create a common outlook for international readers (Ito, 2020).

English is the international language used in translating Manga and Manhwa. Thus the author is zealous to examine further the relevancy of incorporating these materials to entice students' cognitive reading and writing strategies. Despite the growing popularity of international Manga and Manhwa, the author reviewed a limited body of literature to seek further discussion in English learning and literacy. In this conceptual paper, the author explains the use of Multimodality and Dual-coding theory in Manga and Manhwa to reach a threshold level of reading competence. More importantly, the author wants to examine the potentials and problems that have been identified in the area of language enhancement and literacy. Finally, the author demonstrates the implementation of online Manga and Manhwa in language learning and literacy used in the classroom to foster cognitive reading and writing strategies.

\section{Literature Review}

\section{The rise of Manga and Manhwa in Literacy Practices}

In recent years, Japan and Korea are now expanding in promoting their culture and identity globally through entertainment. Japan is known for its Manga with countless genres that vary with readers. At the same time, Korea is known for its impact on media development such as YouTube on the success of K-pop, and now they are delving into comics called Manhwa (Also known as Webtoons) (Jang \& Song, 2017; Bryce, 2009). International fans claimed their devotion to these reading materials is due to storyline intensity and complexity with unpredictable endings (Ito, 2020). Both Manga and Manhwa has promoted a cultural communication establishing a global fandom. Since English is the global language used, the reading materials and the fandom websites, are written in the English language to cater to international readers (Ratnasari, Mayasari \& Wijaya, 2018). In Japan, English-language scholarship on Manga has often been governed and regulated by disciplinary demands and expectations. Manga has often been discussed as part of Japanese popular culture as a gateway for insight into Japan's more nuanced aspects worldwide (Suzuki, 2020).

Meanwhile, in Korea, Manhwa (Webtoon) are now being offered to 18 million global readers since 2014 in the English language, but recently has provided various languages such as Chinese, Taiwanese, Thai, and Indonesian (Jang \& Song, 2017). The very fact that these communities used the English language to translate and interact globally has prompted cognitive reading and writing strategies. As such reading, therefore, involves identifying genre, formal structure, and topic, all activating the scheme and allowing the reader to understand the text (Swales 1990: 89; Wahyono, 2019).

\section{Multimodality and Dual-coding Theory in Manga and Manhwa}

The constant evolution of literacy is genuinely challenging, and there is an urgent need to embrace changes that come with this development. The need for pedagogical practices that support these dynamic changes is essential for a better teaching and learning environment (Rajendra, 2015).

This is where Multimodality falls into place with the use of graphic novels. Multimodality emphasizes the importance of the various modes of semiotics and the 
language at the expense of construing meaning in each social context. The representation produced can be seen around like pictures, music and gestures are emphasized, thereby placing a new emphasis on the multi-semiotic complexity (Rajendra, 2015). A graphic novel such as Manga and Manhwa uses multi-modal by nature to embrace varied modes like images, words, and colours. In today's highly visual world, learners are exposed to a multimodal environment in print and on-screen; therefore, they have allowed the graphic novel to promote many literacies; progressive, critical, and visual literacies. A graphic novel is an ideal example of the multi-modal medium as it uses both words and pictures for communication, requiring the audiences to both "Read and see" (Suzuki, 2020). Moreover, numerous scholars of Manga and Manhwa have used Multimodality to be applied in their pedagogical practice to honour learners' comprehension and cognitive strategies (Rejendra, 2015; Jang \& Song, 2017; Kultura, 2017; Suzuki, 2020; Ito, 2020).

Next, the dual-coding theory has been frequently associated in studies dealing with comics, and graphic novel (Mei-ju, Yun Hung, \& Ching-chi, 2015; Rejendra 2015). In brief, this theory was introduced by Alla Paivio in 1971 noted that we could learn materials in two ways: Verbal association and visual imaginary. This theory emphasized that the linguistic coding system is called the verbal system, whereas the nonverbal coding is called the imagery system. The theory assumes that both systems are used to represent information. The ability to code information two diverse ways increases the chance of remembering items read compared to only code one way (Clark \& Paivio, 1991). In this context, Manga and Manhwa support the notion of Paivio's DCT as the text embraces interchangeability between words and images.

\section{Online Manga and Manhwa to Entice Cognitive Reading and Writing Skills: The Potentials}

Over past few decades, comics or "graphic novels" in general has garnered an unmeasurable number of readers which have begun to be valued by educators, librarians, and scholars and have been incorporated into school curriculums spanning from grade school to higher education (Suzuki, 2020). Over the same decade, Manga has circulated globally, gaining prominence in many countries and geographic regions followed by its counterpart, Manhwa (Jang \& Song, 2017; Suzuki, 2020). Thus, this section will further unravel the potentials incorporating online Manga and Manhwa to entice cognitive reading strategies.

Online Manga and Manhwa support visual literacy. Manga and Manhwa have overly exaggerated expressions, styles, and communication. Using this type of graphic novel could help learners to recognize and comprehend ideas and concepts through images. The explicitness and richness of Manga and Manhwa's drawings provoke readers' ability in comprehending and decoding the meaning of images and symbols (Ito, 2020). Using these images can help educators entice class engagement in constructing meaning and active participation in search of meaning. While traditional literacy skills are pertinent in comprehending images, visual literacy can boost further the skill (Gillenwater, 2012). Gillenwater (2012) further asserts that "developing skills in visual literacy augment a person's ability to interpret his or her world considerably, by providing additional modes of making meaning" (p.33). Hence, it is believed that Manga and Manhwa can hone students' visual literacy just by observing the images.

Online Manga and Manhwa support different learning styles. In recent years as compared to conventional learning styles, new learning styles models have incorporated 
computer and internet-based instructional approaches to facilitate teaching and learning environment (El-Bishouty et al., 2018). Having unlimited access to the internet gives both the teachers and learners the upper hand to explore various reading materials. According to the Felder-Silverman (1988) model, classifies students' learning styles into four components: sensing or intuitive, visual, or verbal, active, or reflective, and, sequential or global. For instance, in Manga and Manhwa, visual or verbal learners can interplay images and words in the storyline. On the other hand, active learners could do group activities by dissecting graphic novels' content together. In contrast, independent learners could interpret the meanings in the novel on their own. Next, for sequential learners, this type of reading material appeals to them as the storyline is organized in sequence to facilitate a coherent plot. For global learners, they could interact with fandoms worldwide to comprehend a wholesome narrative of graphic novels (Rejendra, 2015). The varied layout of Manga and Manhwa support various learning styles through proper instructional strategies. Henceforth, allowing the learners to develop a procedural and substantive plan in attaining their goal in reading the specific genre.

Online Manga and Manhwa promote the reading of various genres. The core reason that raised Manga and Manhwa's popularity is due to their variety of genres offered (Murakami, 2009; Ito, 2020). These genres can be divided into five common types; Shonen (targeted at tween and teen boys), Shoujo (targeted at tween and teen girls), Seinen (targeted at adult men (18+)), Josei (targeted at adult women (18+)), and Kodomomuke (targeted at young children) (Murakami, 2009). On the other hand, Manhwa offers a similar genre as Manga as it was influenced by the Japanese that brought the culture in their country. The varied range of genres promoted in Manga and Manhwa is to educate readers with specific knowledge; hence the storylines and characters serve this purpose (Murakami, 2009). The main genres can be narrowed down into few specific themes depending on the reader's preference, which could be about hobbies, pastimes, sports and many more; volleyball, pastries, cooking or even gambling (Bryce, 2009). Although Mangas and Manhwas serve mostly entertainment, they play a pivotal role in education, especially in providing accurate information on their specific areas (Murakami, 2009; Jang \& Song, 2017). Since the 1970s, graphic novels were developed as the hybrid of education and entertainment. The plot and characters in the genres are more entertaining and independent of the knowledge of the graphic novel conveys (Murakami, 2009). Thus, Manga and Manhwa help in tapping learners' prior knowledge in searching for existing schemata.

Online Manga and Manhwa allow easy comprehension. It exposes the learners to reallife interaction by using dialogues to deliver the pieces of information. The conventions of graphic novels can also be used to determine the tone and mood of the characters shown (Rejendra, 2015). Similarly, comics texts are linguistically appropriate, and aesthetic pictures can help make the texts comprehensible (Mei-Ju, Yung-Hung, \& Ching-chi, 2015). Aside from the interaction, Rejendra (2015) also emphasized that graphic novels writers encourage readers to be exposed to various items such as diction, imagery, syntax, and structure. With the exposure of these elements such as italics, speech balloons, panels, bold and unique effect words, the readers can construe meanings and understand the text better than traditional texts. The students' texts in the classes contain a wide variety of linguistic characteristics typically occurring English conversation (Howell, 2014). Therefore, from the discussion, Manga and Manhwa would allow learners to make sense of the material they are reading, 
eventually helping them expand their schemata by connecting their knowledge and information received.

\section{Online Manga and Manhwa to Entice Cognitive Reading Skills: The Problems}

Despite Manga and Manhwa's positive views, the reception that comics get in educational circles is not always bright. The effectiveness of using this genre in educational practice is still questionable. During the 1950s in the United States, comics received harsh criticism by the community. Popular comic books were burned, and such popular characters of Batman and Robin were accused of the spread of homosexuality, Wonder Woman of being a bad example for girls, and Superman with his supernatural power of promoting a strange sense of reality (Yildirim, 2013). Comics, in general, is viewed as an interference with school learning, Wertham (1954) cited in Mei-ju, Yun-Hung, and Ching-chi (2015) in his book "Seduction of the Innocent" severely quoted that "comic books are the death of reading. "Hence, it is believed that the society is still sceptical in graphic novels, comics, Manga and Manhwa as a medium to encourage reading.

Another main problem for Manga and Manhwa is the choice of reading materials. It is important to note that the selection of graphic novels must be aligned with the predetermined criteria of the country's teaching philosophy. In general, comics have often been accused of depicting and illustrating explicit scenes of violence and sex that might danger the young learners (Yildirim, 2013; Rejendra, 2015), in other words, Manga and Manhwa are not exceptional. On top of that, integrating an online medium to read Manga and Manhwa could be a double-edged sword if it is not being taught properly. Students or learners can roam freely with different genres that are not appropriate for them to read. Hence, teachers play a pivotal role in supervising the selection of graphic novels that are appropriate to the learners' needs (Rejendra, 2015). Moreover, the content and ageappropriateness of these genres must also be examined and strictly vetted.

\section{The execution of incorporating online Manga and Manhwa in Class}

The author adopted a strategy suggested by Howell (2014) using Manga in teaching English as a foreign language among Japanese students. This research has succinctly covered the four aspects of the English assessment (Speaking, Listening, Reading, and Writing), however, in this section, the author would like to focus on the reading and writing components implemented by Howell (2014), as highlighted in table 1:

\begin{tabular}{|c|l|l|}
\hline Sequence & Activity & Group Size during Activity \\
\hline 1. & Peer reading of rough translations (Warm-up) & Individual class members \\
\hline 2. & Dictation & Individual class members \\
\hline 3. & Imaginative Writing & Pairs \\
\hline 4. & Performative reading 1 & Large groups \\
\hline 5. & Performative reading 2 & Whole class \\
\hline 6. & Silent reading & Individual class members \\
\hline 7. & Rough translation & Individual class members \\
\hline
\end{tabular}

Table 1: Sequence of Lesson Activities

The author would like to focus on the three highlighted components incorporated in English translated Manga and Manhwa. Firstly, the imaginative Writing in pairs. In this activity, the 
teacher will distribute a photocopy of any interesting pages of Manga or Manhwa retrieved online with dialogue blanked out or untranslated dialogues. Their job is to imagine and write the dialogue in English. The students are given 20-25 minutes for the activity. Howell (2014) repeatedly urged students to be creative in creating dialogue, jokes and parodies are most welcome. Afterwards, the next session, the students are required to read aloud their dialogue to their classmates. The class needs to be divided into three or four larger groups, each standing in a circular formation and free to find a comfortable spot for them to read aloud. Their native language is not discouraged, as it is necessary to clarify the English dialogue's meaning. When each pair in the group had completed its read-aloud, the group's members need to choose which pair's dialogue they liked the most. Lastly, the third session will be conducted in front of the whole class. They are encouraged to be dramatic as they like in their readings to get the gist of the characters' emotions, but most importantly, their voice needs to be loud and clear. Ito (2020) mentioned that Manga and Manhwa allow readers to indulge in the rich emotions and expressions depicted in the drawings, symbols, and colours used. Lastly, the teacher should select one interesting sentence and write it on the board. The teacher needs to comment on the sentence and ask the whole class to repeat the revised sentence. Before dismissing the class, the teacher will give another chapter of Manga or Manhwa for the students to read, to be discussed during the next class. The activity's sequence can be simplified based on figure 1 below:

Pair work- Create a creative dialogues based on the printed online Manga and Manhwa

Large group - Read aloud in a large groups (4-5 members) and choose the best pairs

Whole class - The chosen pairs need to read aloud infront of the whole class

Whole class- The teacher will jot down few interesting dialogues on the board to be discussed in class

Individual - Teacher will give another online Manga or Manhwa for students to read

Figure 1: Sequence of the activity

These components are aligned with the notion of cognitive reading and writing strategies. It is believed that the exposure of cognitive strategies promotes and enhances critical and creative thinking, as agreed by Tierney et al. (1989) "reading and writing in combination have the potential to contribute in powerful ways of thinking" (p. 166)

\section{Conclusion}

In learning foreign languages, it is crucial to expose the students to a real-life situation to get the actual feeling of using the language. Online Manga and Manhwa is an excellent 
supplementary material to encourage learners to learn languages. The mixture of exaggerated images, symbols, expressions, colours, and dialogues will keep them entertained and hooked them to indulge in reading. With the right selection of online Manga and Manhwa and meticulously drafted lesson plan, reading and Writing will not be dreadful. Students' minds should be liberated to write down their thoughts effectively; hence, honing their cognitive reading and writing strategies will help their minds think critically actively. Art Spiegelman (an American cartoonist) quoted, "Comics are a gateway drug to Literacy."

\section{References}

Bryce, M. (2014). Manga as an Educational Medium. International Journal of the Humanities, 7(November). https://doi.org/10.18848/1447-9508/CGP/v07i10/42761

Clark, J. M., \& Paivio, A. (1991). Dual Coding Theory and Education. Education Psychology, 3(3), 149-210.

Gillenwater, C. (2012). Graphic novels in advanced English/language arts classrooms: A phenomenological case study. Unpublished PhD, The University of North Carolina at Chapel Hill.

Howell, P. (2008). Using Manga in Teaching English as a Foreign Language. Howell, 2001, 195204.

Ito, T. (2020). The Benefits of Anime Background in Comprehension with Manga in Japanese. August.

Jang, W. (2017). WEBTOON AS A NEW KOREAN WAVE IN THE PROCESS OF GLOCALIZATION. Kritika Kultura, 29(2017), 168-187.

Mei-Ju, C., Yung-Hung, H., \& Ching-chi, C. (2015). Will Aesthetics English Comic BooksMake Junior High School Students Fall in Love with English Reading? Universal Journal of Educational Research, 3(10), 671-679. https://doi.org/10.13189/ujer.2015.031003

Rajendra, T. R. (2015). Multimodality in Malaysian Schools: The Case for the Graphic Novel. $3(2)$.

Ratnasari, N., Mayasari, L., \& Wijaya, S. D. (2018). The Effectiveness of Webtoon to Develop Students' Writing Skill in Narrative Text of Tenth Grader in SMK Pgri 13 Surabaya. Tell Journal, 6(2), 88-96.

Suzuki, S. (2020). Teaching Manga: A Medium-Specific Approach Beyond Area Studies. MANGA!: Visual Pop-Culture in ARTS Education. InSEA Publication. 208-215. E-ISBN: 978-989-54683-7-9. ISBN: 978-989-54683-6-2. DOI: 10.24981/2020-3

Yamada, M., Budiarto, R., Endo, M., \& Miyazaki, S. (2004). Comic Image Decomposition for Reading Comics on Cellular Phones. Comic Image Decomposition for Reading Comics on. June 2014.

Yildirim, A. H. (2013). Using Graphic Novels in the Classroom. 2008, 118-131. 
INTERNATIONAL JOURNAL OF ACADEMIC RESEARCH IN BUSINESS AND SOCIAL SCIENCES Vol. 11, No. 7, 2021, E-ISSN: 2222-6990 @ 2021 HRMARS

\section{Appendix}
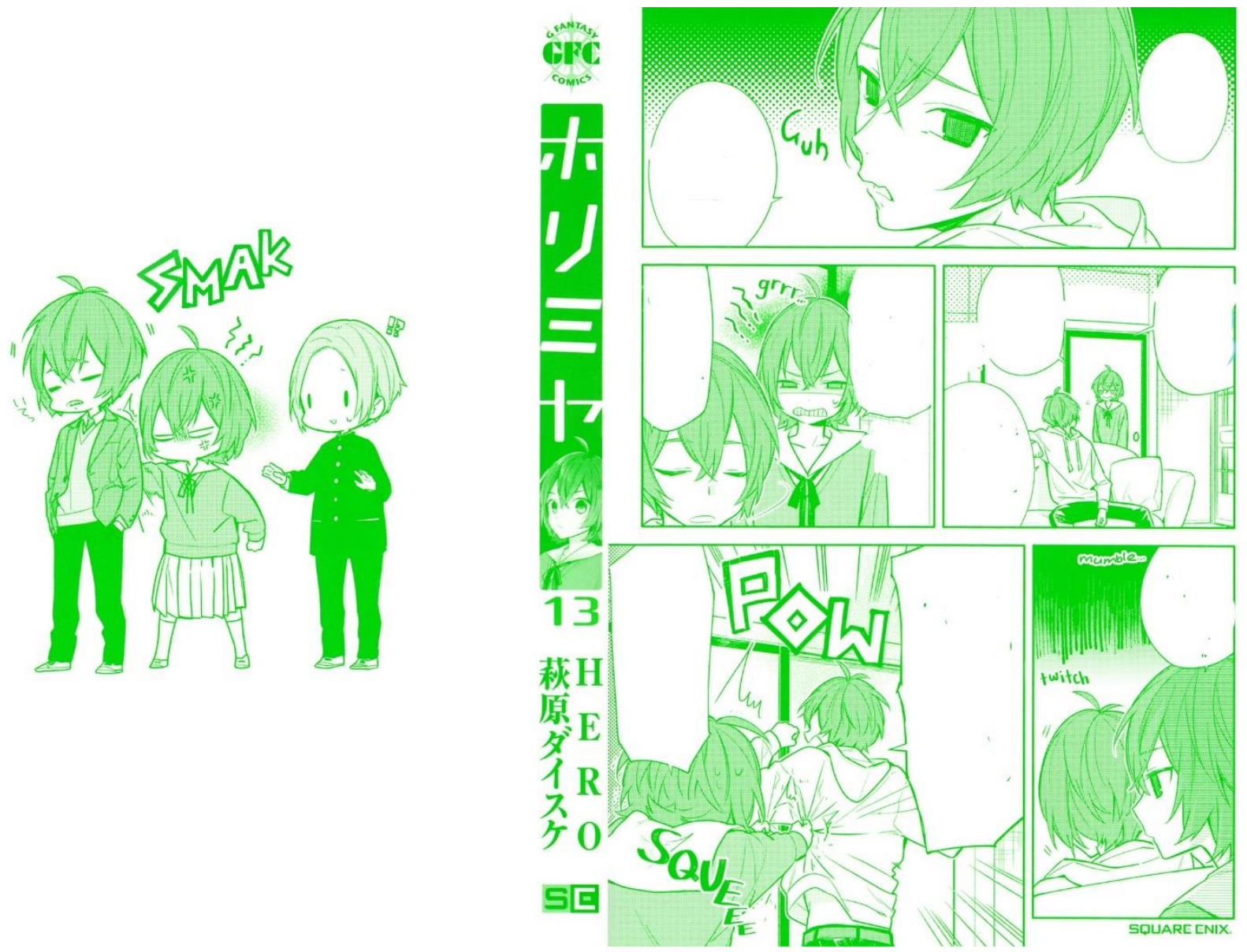

Example of blanked out Manga: Horimiya 
INTERNATIONAL JOURNAL OF ACADEMIC RESEARCH IN BUSINESS AND SOCIAL SCIENCES Vol. 11, No. 7, 2021, E-ISSN: 2222-6990 @ 2021 HRMARS

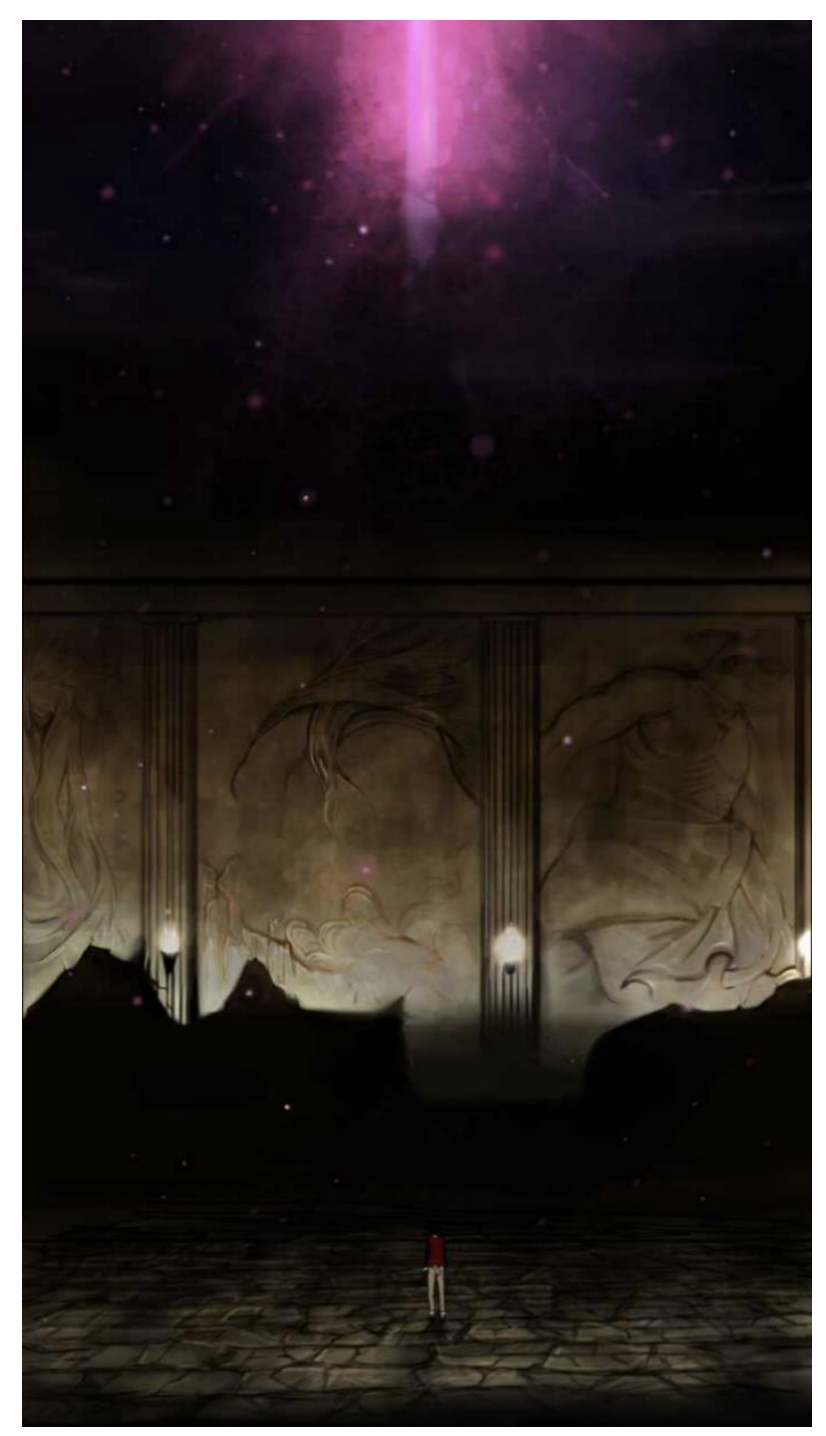


INTERNATIONAL JOURNAL OF ACADEMIC RESEARCH IN BUSINESS AND SOCIAL SCIENCES Vol. 11, No. 7, 2021, E-ISSN: 2222-6990 @ 2021 HRMARS

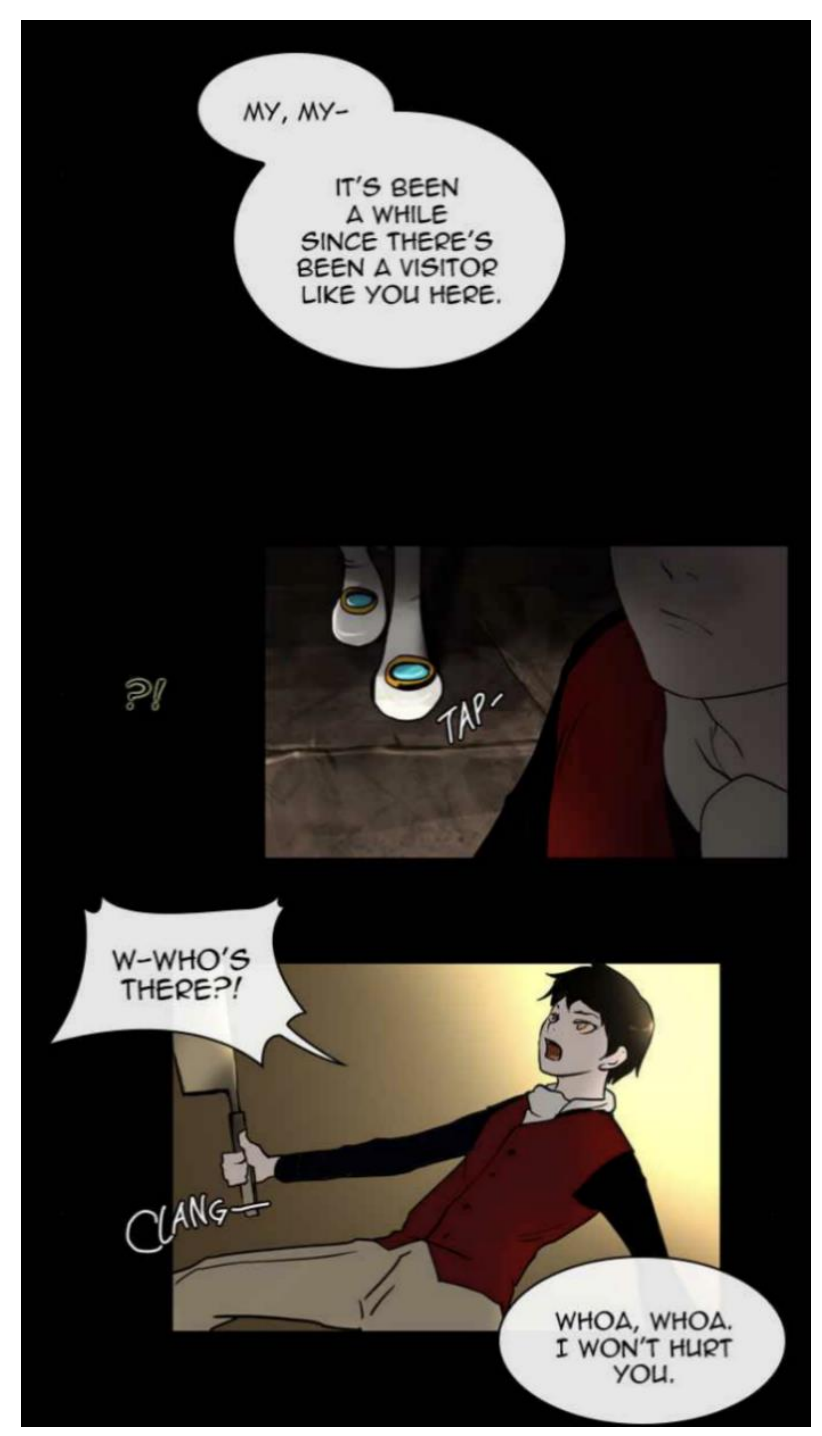


INTERNATIONAL JOURNAL OF ACADEMIC RESEARCH IN BUSINESS AND SOCIAL SCIENCES Vol. 11, No. 7, 2021, E-ISSN: 2222-6990 @ 2021 HRMARS

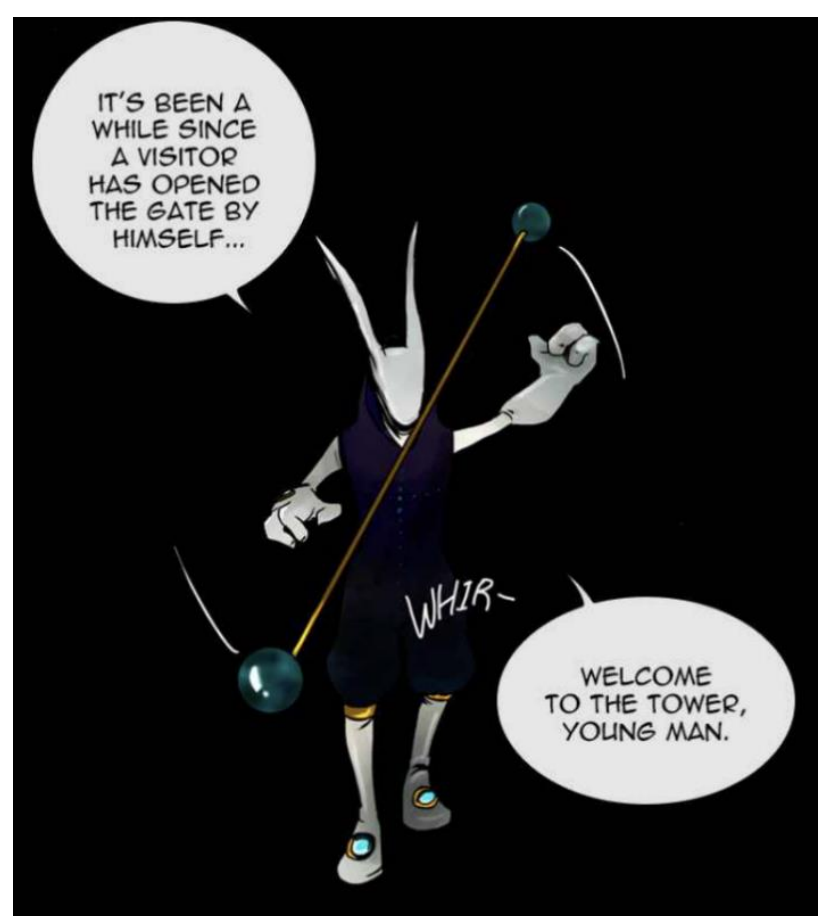

R=IS IT A MONSTERP

$\triangle \mathrm{AW} \mathfrak{I D}_{000}$

INSIOE TLES TOWISBoo\&

MY NAME IS HEADON. I'M THE GUARDIAN OF THE FIRST FLOOR OF THE TOWER. 
INTERNATIONAL JOURNAL OF ACADEMIC RESEARCH IN BUSINESS AND SOCIAL SCIENCES Vol. 11, No. 7, 2021, E-ISSN: 2222-6990 @ 2021 HRMARS

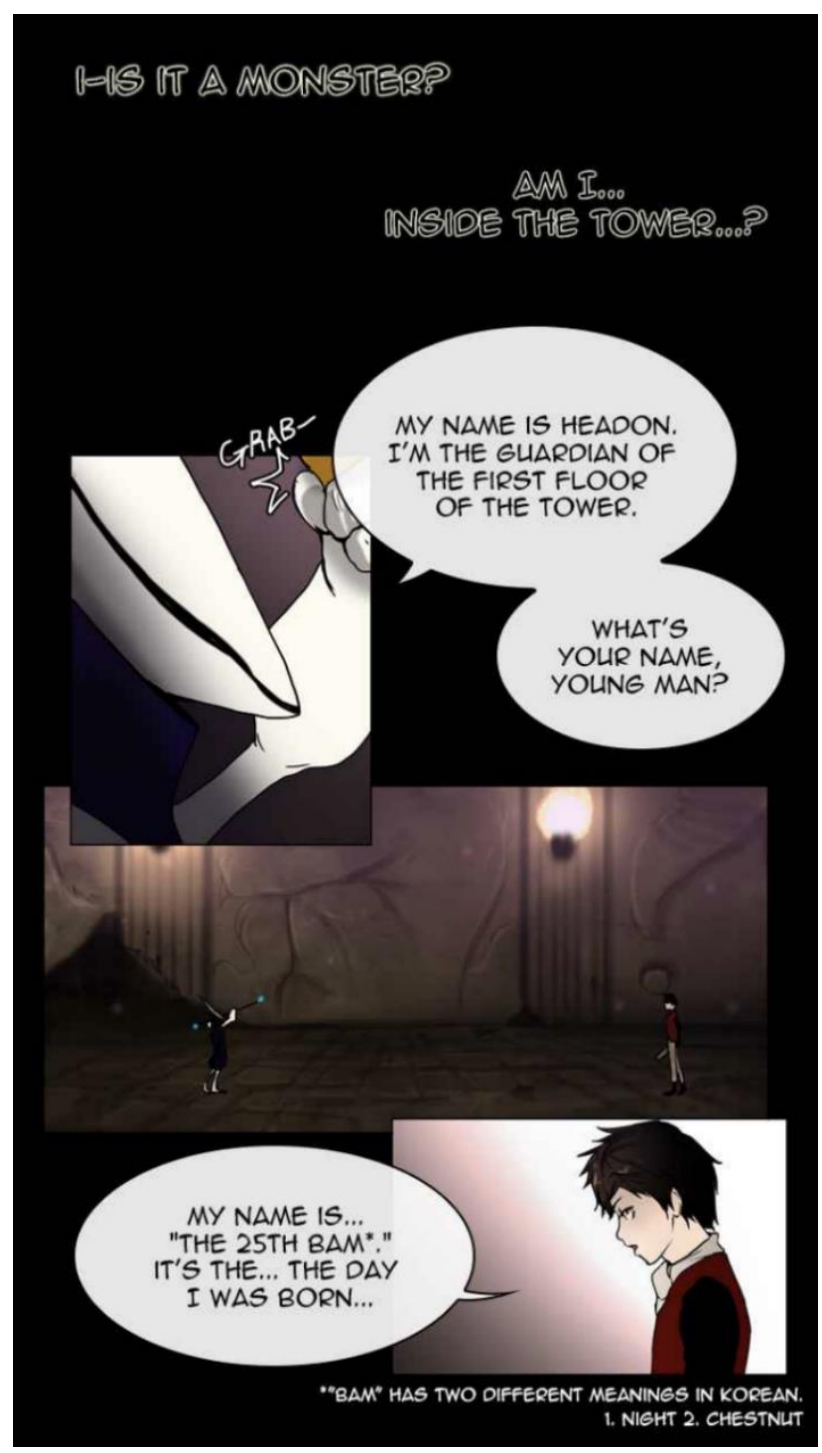

Example of online Manhwa: Tower of God 

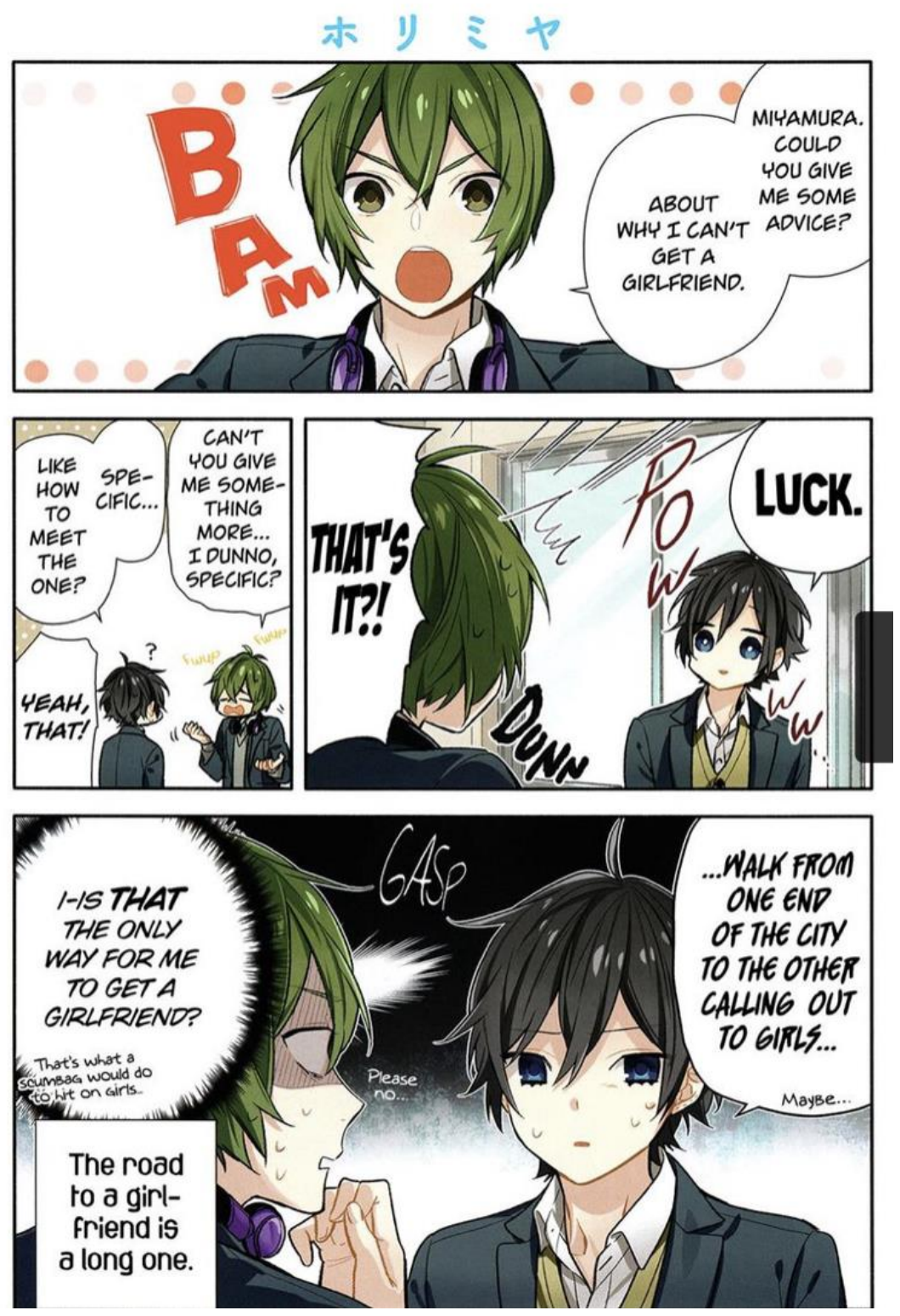

Example of online coloured Manga: Horimiya 